\title{
Improving Prediction Algorithms for Cardiometabolic Risk in Children and Adolescents
}

\author{
Ulla Sovio, ${ }^{1}$ Aine Skow, ${ }^{1}$ Catherine Falconer, ${ }^{1}$ Min Hae Park, ${ }^{1}$ \\ Russell M. Viner, ${ }^{2}$ and Sanjay Kinra ${ }^{1}$ \\ ${ }^{1}$ Department of Non-Communicable Disease Epidemiology, London School of Hygiene and Tropical Medicine, Keppel Street, \\ London WC1E 7HT, UK \\ ${ }^{2}$ General and Adolescent Paediatrics Unit, Institute of Child Health, University College London, 30 Guilford Street, \\ London WC1N 1EH, UK
}

Correspondence should be addressed to Ulla Sovio; ulla.sovio@lshtm.ac.uk

Received 12 February 2013; Accepted 9 June 2013

Academic Editor: Ajay K. Gupta

Copyright (C) 2013 Ulla Sovio et al. This is an open access article distributed under the Creative Commons Attribution License, which permits unrestricted use, distribution, and reproduction in any medium, provided the original work is properly cited.

\begin{abstract}
Clustering of abnormal metabolic traits, the Metabolic Syndrome (MetS), has been associated with an increased cardiovascular disease (CVD) risk. Several algorithms including the MetS and other risk factors exist for adults to predict the risk of CVD. We discuss the use of MetS scores and algorithms in an attempt to predict later cardiometabolic risk in children and adolescents and offer suggestions for developing clinically useful algorithms in this population. There is little consensus in how to define the MetS or to predict future CVD risk using the MetS and other risk factors in children and adolescents. The MetS scores and prediction algorithms we identified had usually not been tested against a clinical outcome, such as CVD, and they had not been validated in other populations. This makes comparisons of algorithms impossible. We suggest a simple two-step approach for predicting the risk of adult cardiometabolic disease in overweight children. It may have advantages in terms of cost-effectiveness since it uses simple measurements in the first step and more complex, costly measurements in the second step. It also takes advantage of the continuous distributions of the metabolic features. We suggest piloting and validating any new algorithms.
\end{abstract}

\section{Introduction}

Obesity is associated with a number of diseases, such as type 2 diabetes (T2D), cardiovascular disease (CVD), cancers, asthma, osteoarthritis, chronic back pain, and sleep apnoea [1]. As childhood obesity prevalence has risen markedly in recent decades [2], indicators of early development of some of these diseases are increasingly being seen in childhood and adolescence. For example, the lowest estimated prevalences of impaired glucose tolerance, hypertension, and raised total cholesterol in obese 5-18-year-old children in the European Union in 2006 were $8.4 \%, 21.8 \%$, and $22.1 \%$, respectively [3]. Obesity and its associated health risk factors track strongly from childhood into adulthood [4]. Therefore, identification of children at an increased risk of developing obesity-related diseases is critical for early prevention.

Various algorithms have been developed for adults to provide individual predictions of risk of obesity-related diseases, particularly of cardiometabolic risk leading to CVD [5-15]. These include the widely used Framingham Risk Score [6, 7], which uses information on age, sex, blood pressure, total cholesterol (TC), high density lipoprotein cholesterol (HDLC), diabetes, and current smoking behaviour to give an estimate of 10 -year CVD risk in adults aged $\geq 20$ years.

Attempts have also been made to develop similar algorithms to predict cardiometabolic risk in children [1627], and most of them focus on identifying the Metabolic Syndrome (MetS, the clustering of abnormal metabolic traits associated with CVD risk) $[28,29]$. However, these algorithms are not widely used. There is little consensus on the criteria for defining the MetS in children and adolescents, and most algorithms have not been validated. The existing childhood MetS definitions have been derived from adult definitions assuming that the conditions are related over the life course, while the utility and predictive value of MetS in children have not yet been fully established [30]. In this 
review, we examine the benefits and limitations of MetS scores and algorithms that have been developed to predict later cardiometabolic risk in children and adolescents and offer suggestions for developing clinically useful algorithms in this population. Such algorithms could aid primary care professionals in the identification of children at high risk of obesity-related diseases and would be an important tool in childhood obesity management.

\section{Using Metabolic Syndrome (MetS) Scores to Predict Cardiometabolic Risk}

The MetS in adults is characterised by obesity (often assessed by large waist circumference (WC)), high triglycerides (TG), low HDL-C, high blood pressure, and high glucose levels [25]. The prevalence of the MetS increases with age. In children and adolescents, the thresholds for the individual variables to define these "high" and "low" levels depend on the age of the population and the MetS definition applied.

Notably, because there is no consensus about the definition of MetS in children, it can be difficult to make consistent and accurate diagnoses [27]. Due to the lack of universal MetS definition and for the sake of retaining statistical power, construction of continuous MetS scores (cMetS) has gained popularity [31]. Many algorithms which predict cardiometabolic risk in children are based on these MetS scores, with children who are classified as having MetS or children with a high value of cMetS being flagged as having an increased future cardiometabolic risk. Studies that have used either continuous [16] or binary [24, 26, 27] MetS definitions/scores to assess or predict future cardiometabolic risk have been reviewed previously. These studies do not always explicitly state the future disease that they are trying to predict (e.g., CVD); instead, terms such as cardiovascular or cardiometabolic risk are widely used. The association between MetS characteristics in childhood and increased adult risk of CVD may largely be due to tracking of obesity and other MetS characteristics from childhood into adulthood [4].

One recent example of a MetS definition is from the International Diabetes Federation (IDF), which modified a definition originally developed for adults. The IDF has age-specific definitions of MetS $(6-<10,10-<16$, and $\geq 16$ years $)[25,26]$ which is an improvement over earlier definitions that did not include age stratification $[26,27]$. Except for the youngest age group (where MetS is not defined, but further measurements for obese children with a family history of CVD or related conditions are recommended), the IDF definition produces a binary outcome identifying children as having MetS if the child has high WC and exceeds threshold levels for at least two of the following four risk factors: high TG, low HDL-C, high SBP/DBP, and high glucose. In that sense, it is similar to earlier MetS definitions in paediatrics $[16,24,26$, 27]. However, the IDF definition has been regarded as the most appropriate binary MetS definition in children since it applies different criteria for each age group, acknowledging that blood pressure, lipid levels, and anthropometric variables change with age and pubertal development [27]. If the IDF definition in children becomes widely accepted, it could be used to aid in the identification of children at an elevated cardiometabolic risk. Alternatively, to maximise the use of information and statistical power, the underlying continuous risk factors that compose the IDF definition from age 10 years could be turned into a cMetS. The threshold indicating a high value of this score could then be defined for each age group or ever for each age (in years) to increase accuracy.

\section{Algorithms for Cardiometabolic Risk Prediction Which Include Items in addition to MetS Components}

Some algorithms for predicting cardiometabolic risk in children include additional characteristics to metabolic traits that are established risk factors of CVD. Examples include models which additionally use ethnicity, family history of disease, fitness level, or smoking status to compute a final risk score (Table 1) [18-23, 32-36]. In these algorithms, however, the choice of additional non-MetS components is rarely justified and in many cases appears to be based solely on availability of data or characteristics identified in studies restricted to adult populations.

Diagnostic test results for most of the algorithms developed in children have not been published, in most cases due to the lack of current or subsequent clinical outcomes (such as CVD) against which they could have been tested. We did, however, find two exceptions. One study-which predicted the probability of developing atherosclerotic lesions in the coronary artery and abdominal aorta based on age, sex, smoking, BMI, hypertension, hyperglycemia, HDL cholesterol, and non-HDL cholesterol-reported an area under the receiver-operating curve (AUC) of 0.78 for the risk of coronary artery lesions and of 0.84 for abdominal aorta lesions [21]. Another study tested a score based on the refined American Diabetes Association (ADA) criteria for glucose intolerance in a clinical high-risk population from Birmingham; this study reported sensitivity of $100 \%$, specificity of $57 \%$, and positive predictive value (PPV) of 36\% [36].

We did not identify any validation studies of these risk algorithms in populations other than those in which they were first developed or applied. Without these two important steps of testing and validation, it is impossible to compare the performance of different algorithms to one other. Testing and validation are needed to develop consensus on what is the best method for predicting cardiometabolic risk in children.

\section{Improving Cardiometabolic Risk Algorithm for Children}

Using a summary score to predict cardiometabolic risk in children, like all the MetS scores reviewed here, is appealing because it reduces different metabolic dimensions into a single variable. However, certain assumptions have to be made when this approach is used [31]. Each item included in the score is assumed to be equally important (unless weighting is used) and exchangeable with any other item. For example, $1 \mathrm{SD}$ increase in blood pressure is assumed to be 
TABLE 1: Cardiometabolic risk scores developed for children and adolescents.

\begin{tabular}{|c|c|c|c|c|c|c|c|c|}
\hline & $\begin{array}{c}\text { Andersen and } \\
\text { Haraldsdottir } \\
1993 \text { [32] }\end{array}$ & $\begin{array}{c}\text { ADA } 2000 \\
{[22,36]}\end{array}$ & $\begin{array}{l}\text { Rodríguez- } \\
\text { Morán et al. } \\
2004 \text { [23] }\end{array}$ & $\begin{array}{l}\text { McMahan et } \\
\text { al. } 2005[21]\end{array}$ & $\begin{array}{c}\text { Andersen } \\
\text { et al. } 2006 \\
{[33]}\end{array}$ & $\begin{array}{l}\text { Reed et al. } \\
2007[18]\end{array}$ & $\begin{array}{c}\text { Brambilla } \\
\text { et al. } 2007 \\
\text { [19] Bueno } \\
\text { et al. 2007 } \\
{[20]}\end{array}$ & $\begin{array}{c}\text { Andersen } \\
\text { et al. } 2010 \\
{[35]}\end{array}$ \\
\hline$N$ & 203 & 66 & 965 & 2,575 & 1,732 & 242 & 153 & 210 \\
\hline Age range (years) & $15-19$ & $5-17$ & $10-18$ & $15-34$ & $9-15$ & $9-11$ & $9-13$ & $9-10$ \\
\hline Sex (\% male) & 43 & 29 & N/A & N/A & 47 & 50 & 52 & 54 \\
\hline Nationality or ethnicity & Danish & $\begin{array}{l}\text { South } \\
\text { Asian, } \\
\text { British, } \\
\text { and } \\
\text { African } \\
\text { Caribbean }\end{array}$ & Mexican & & $\begin{array}{l}\text { Danish, } \\
\text { Estonian, } \\
\text { and } \\
\text { Portuguese }\end{array}$ & Canadian & Spanish & Danish \\
\hline $\begin{array}{l}\text { Stratification, adjustment, } \\
\text { or standardisation }\end{array}$ & Sex & $\begin{array}{l}\text { Age and } \\
\text { sex (for } \\
\text { BMI) }\end{array}$ & $\begin{array}{l}\text { Age and sex (for } \\
\text { BMI, BP, and } \\
\text { TG) }\end{array}$ & & $\begin{array}{l}\text { Age, sex, } \\
\text { and } \\
\text { country }\end{array}$ & Age, sex & $\begin{array}{l}\text { Sex (for } \\
\text { obesity) }\end{array}$ & Sex \\
\hline Exclusions & & & & & & & Nonobese & \\
\hline Score name & $\begin{array}{l}\text { Total risk } \\
\text { score }\end{array}$ & $\begin{array}{l}\mathrm{T} 2 \mathrm{D} \\
\text { criteria }\end{array}$ & REGODCI & PDAY & $\begin{array}{l}\text { Composite } \\
\text { score }\end{array}$ & $\begin{array}{c}\text { Healthy } \\
\text { Heart } \\
\text { Score }\end{array}$ & MIRACLE & $\begin{array}{c}\text { Composite } \\
\text { risk factor } \\
\text { score }\end{array}$ \\
\hline \multicolumn{9}{|c|}{ Risk factor included [Y = yes] } \\
\hline Age & & & & $\mathrm{Y}$ & & & & \\
\hline Sex & & & & $\mathrm{Y}$ & & & & \\
\hline BMI & & $\mathrm{Y}$ & $\mathrm{Y}$ & $\mathrm{Y}$ & & $\mathrm{Y}$ & $\mathrm{Y}$ & \\
\hline$W C^{*}$ & & & & & & & $Y$ & \\
\hline Skinfolds & $\mathrm{Y}$ & & & & $\mathrm{Y}$ & & & $\mathrm{Y}$ \\
\hline$S B P^{*}$ & $Y$ & & $Y$ & & $Y$ & $Y$ & $Y$ & $Y$ \\
\hline$D B P^{*}$ & $Y$ & & $Y$ & & & $Y$ & $Y$ & \\
\hline Hypertension ${ }^{*}$ & & $Y$ & & $Y$ & & & & \\
\hline $\mathrm{TC}$ & $\mathrm{Y}$ & & & & & & & \\
\hline$H D L-C^{*}$ & $Y$ & & $Y$ & $Y$ & & & & \\
\hline Non-HDL-C & & & & $\mathrm{Y}$ & & & & \\
\hline TC:HDL-C & & & & & $\mathrm{Y}$ & & & $\mathrm{Y}$ \\
\hline$T G^{*}$ & $Y$ & & $Y$ & & $Y$ & & & $Y$ \\
\hline Glucose $e^{*}$ & & & $Y$ & & & & & \\
\hline Dyslipidemia & & $\mathrm{Y}$ & & & & & & \\
\hline Hyperglycemia & & & & $\mathrm{Y}$ & & & $\mathrm{Y}$ & \\
\hline Insulin resistance & & & & & $\mathrm{Y}$ & & & $\mathrm{Y}$ \\
\hline $\mathrm{T} 2 \mathrm{D}$ & & & & & & & $\mathrm{Y}$ & \\
\hline PCOS & & $\mathrm{Y}$ & & & & & & \\
\hline Smoking & $\mathrm{Y}$ & & & $\mathrm{Y}$ & & & & \\
\hline Fitness & & & & & $\mathrm{Y}$ & $\mathrm{Y}$ & & $\mathrm{Y}$ \\
\hline $\mathrm{PA}$ & & & & & & $\mathrm{Y}$ & & \\
\hline $\begin{array}{l}\text { Family history of CVD/ } \\
\text { T2D/Hypertension/obesity }\end{array}$ & & $\mathrm{Y}$ & $\mathrm{Y}$ & & & & Y & \\
\hline SGA & & & & & & & $\mathrm{Y}$ & \\
\hline Birth weight & & & $\mathrm{Y}$ & & & & & \\
\hline Ethnicity & & $\mathrm{Y}$ & & & & & $\mathrm{Y}$ & \\
\hline Acanthosis nigricans & & $\mathrm{Y}$ & & & & & $\mathrm{Y}$ & \\
\hline
\end{tabular}

${ }^{*}$ MetS components are given in italics. 
equivalent with 1 SD increase in TG or 1 SD decrease in HDLC. These assumptions are unlikely to reflect reality, and they may be difficult to validate in real datasets.

Instead of using a binary MetS outcome, which is a common practice, a continuous MetS score (cMetS) may be preferable. This can be a sum of individual rankings, sum or mean of z-scores, principal components, or sum of standardised residuals [16]. This approach overcomes problems such as misclassification and low statistical power often related to binary scores. However, if the resulting cMetS is subsequently grouped using cutoffs, like the age-specific IDF MetS definition [26], misclassification may still occur. Researchers have been urged to create and validate population-specific cMetS for children [31]. Although this approach is justifiable, it complicates comparisons between populations.

There are also some general issues concerning screening tools that need to be taken into account when they are applied in clinical practice. If the sensitivity of the tool is not adequate, a considerable proportion of children at risk will not be detected. On the other hand, if specificity of the tool is limited, some children who are not at an increased risk will be captured and may have to go through unnecessary further testing which may cause anxiety to the children and their families. A test with reasonably good sensitivity and specificity may be useful for early identification of children with increased future risk, which in turn may create opportunities for early intervention. For example, in the study which predicted the probability of developing atherosclerotic lesions [21], AUC based on sensitivity and specificity was fairly good, but the results of this study were not replicated.

The applicability of an algorithm should always be piloted in the target population before implementing it, since an algorithm developed in one population may not be useful in another population without modification. For example, some algorithms have been developed in selecting clinical populations [36] or in ethnic groups of a higher risk. This is especially a concern when cMetS is used and when cut-off points for an increased risk are defined without a clinical basis [31].

We suggest development of an algorithm which fully utilises the continuous distributions of metabolic features (e.g., by calculating $\mathrm{z}$-scores). For example, a two-step approach may have advantages in terms of cost-effectiveness. The first step would target a wider range of overweight/obese children, perhaps through primary care, and those who were flagged as overweight (using age, sex, and potentially ethnicity standardised BMI z-score) could be assessed for other easily measurable factors predictive of later cardiometabolic disease, for example, blood pressure. The small group of children that exceed a stringent threshold for a standardised summary score for estimated risk could then be taken forward to the next step. In this next step, more complex, costly, or time-consuming clinical measurements (e.g., lipids, insulin, and glucose) could be taken from referred children and an updated standardised risk score could be calculated. Children with a "high risk" score should be offered specialised weight management interventions if these are available or be monitored regularly and treated when necessary. This approach combines the benefits of the use of continuous metabolic features in the first step while retaining usability through the application of cutoffs for flagging children who are predicted to be at the highest risk.

The suggested algorithm could be based on a fitted prediction model in a large, longitudinal, population-based dataset that covers anthropometric and metabolic data and other relevant risk factors from childhood and adolescence as well as clinical outcomes (T2D, hypertension, and CVD) from adulthood. The algorithm should be validated and refined in other datasets. Once validated, it should be an improvement over existing algorithms because it uses complete information from the continuous distributions of the metabolic risk factors.

Our work using a large UK cohort [37] suggested that age, sex, and ethnicity standardised BMI z-score was the best predictor of having cardiovascular risk factors (elevated glucose, LDL-C, and/or SBP/DBP) present in childhood (submitted manuscript). Based on this work, we created a simple online tool that gives primary care providers guidance on how to treat and appropriately refer children who are overweight. This tool was piloted among future user groups in the UK. Validation against clinical cardiometabolic outcomes in adulthood was not possible using the same cohort due to its young age, but we hope to validate our models in larger, more diverse datasets in the future.

\section{Conclusions}

Several different MetS scores and algorithms which predict adult cardiometabolic risk in children have been developed, but diagnostic test results against a clinical outcome, such as CVD, have not been published for most of them, and they have not been validated in other populations. We suggest a simple two-step approach for predicting risk of adult cardiometabolic disease in overweight children and piloting and validating any new algorithms.

\section{Acronyms}

$\begin{array}{ll}\text { CVD: } & \text { Cardiovascular disease } \\ \text { CHD: } & \text { Coronary heart disease } \\ \text { MetS: } & \text { Metabolic Syndrome } \\ \text { cMetS: } & \text { Continuous metabolic syndrome score } \\ \text { T2D: } & \text { Type } 2 \text { diabetes } \\ \text { BMI: } & \text { Body mass index } \\ \text { WC: } & \text { Waist circumference } \\ \text { SBP: } & \text { Systolic blood pressure } \\ \text { DBP: } & \text { Systolic blood pressure } \\ \text { MAP: } & \text { Mean arterial pressure } \\ \text { TG: } & \text { Triglyceride } \\ \text { TC: } & \text { Total cholesterol } \\ \text { HDL-C: } & \text { High density lipoprotein cholesterol } \\ \text { TC: HDL-C: } & \text { TC/HDL-C ratio } \\ \text { LDL-C: } & \text { Low density lipoprotein cholesterol } \\ \text { IR: } & \text { Insulin resistance } \\ \text { HOMA: } & \text { Homeostasis model assessment } \\ \text { IDF: } & \text { International Diabetes Federation } \\ \text { IGT: } & \text { Impaired glucose tolerance } \\ \text { OGTT: } & \text { Oral glucose tolerance test } \\ \text { PCOS: } & \text { Polycystic ovarian syndrome } \\ \end{array}$


ROC: Receiver operating characteristic

PA: Physical activity

SGA: Smallness for gestational age

PPV: Positive predictive value.

\section{Conflict of Interests}

The authors declare that they have no conflict of interests.

\section{Acknowledgments}

This paper presents independent research funded by the National Institute for Health Research (NIHR) under its Programme Grants for Applied Research programme (RPPG-0608-10035-the Paediatric Research in Obesity Multimodal Intervention and Service Evaluation (PROMISE) programme). The views expressed in this paper are those of the authors and not necessarily those of the NHS, the NIHR, or the Department of Health.

\section{References}

[1] D. P. Guh, W. Zhang, N. Bansback, Z. Amarsi, C. L. Birmingham, and A. H. Anis, "The incidence of co-morbidities related to obesity and overweight: a systematic review and meta-analysis," BMC Public Health, vol. 9, article 88, 2009.

[2] R. Jackson-Leach and T. Lobstein, "Estimated burden of paediatric obesity and co-morbidities in Europe-part 1: the increase in the prevalence of child obesity in Europe is itself increasing," International Journal of Pediatric Obesity, vol. 1, no. 1, pp. 26-32, 2006.

[3] T. Lobstein and R. Jackson-Leach, "Estimated burden of paediatric obesity and co-morbidities in Europe-part 2: numbers of children with indicators of obesity-related disease," International Journal of Pediatric Obesity, vol. 1, no. 1, pp. 33-41, 2006.

[4] M. H. Park, C. Falconer, R. M. Viner, and S. Kinra, "The impact of childhood obesity on morbidity and mortality in adulthood: a systematic review," Obesity Reviews, vol. 13, no. 11, pp. 985-1000, 2012.

[5] P. E. Schwarz, J. Li, J. Lindstrom, and J. Tuomilehto, "Tools for predicting the risk of type 2 diabetes in daily practice," Hormone and Metabolic Research, vol. 41, no. 2, pp. 86-97, 2009.

[6] R. B. D’Agostino Sr., S. Grundy, L. M. Sullivan, and P. Wilson, "Validation of the Framingham coronary heart disease prediction scores: results of a multiple ethnic groups investigation," Journal of the American Medical Association, vol. 286, no. 2, pp. 180-187, 2001.

[7] L. T. Mahoney, T. L. Burns, W. Stanford et al., "Usefulness of the Framingham risk score and body mass index to predict early coronary artery calcium in young adults (Muscatine Study)," American Journal of Cardiology, vol. 88, no. 5, pp. 509-515, 2001.

[8] A. J. Cameron, D. J. Magliano, P. Z. Zimmet et al., "The metabolic syndrome as a tool for predicting future diabetes: the AusDiab study," Journal of Internal Medicine, vol. 264, no. 2, pp. 177-186, 2008.

[9] P. E. H. Schwarz, J. Li, M. Reimann et al., "The finnish diabetes risk score is associated with insulin resistance and progression towards type 2 diabetes," Journal of Clinical Endocrinology and Metabolism, vol. 94, no. 3, pp. 920-926, 2009.
[10] J. Lindström and J. Tuomilehto, “The diabetes risk score: a practical tool to predict type 2 diabetes risk," Diabetes Care, vol. 26, no. 3, pp. 725-731, 2003.

[11] A. Pende, C. Grondona, and S. Bertolini, "Correlation between Progetto Cuore risk score and early cardiovascular damage in never treated subjects," Cardiovascular Ultrasound, vol. 6, article 47, 2008.

[12] R. M. Conroy, K. Pyörälä, A. P. Fitzgerald et al., "Estimation of ten-year risk of fatal cardiovascular disease in Europe: the SCORE project," European Heart Journal, vol. 24, no. 11, pp. 987$1003,2003$.

[13] S. J. Griffin, P. S. Little, C. N. Hales, A. L. Kinmonth, and N. J. Wareham, "Diabetes risk score: towards earlier detection of type 2 diabetes in general practice," Diabetes/Metabolism Research and Reviews, vol. 16, pp. 164-171, 2000.

[14] J. Hippisley-Cox, C. Coupland, J. Robson, A. Sheikh, and P. Brindle, "Predicting risk of type 2 diabetes in England and Wales: prospective derivation and validation of QDScore," British Medical Journal, vol. 338, article b880, 2009.

[15] H. Bang, A. M. Edwards, A. S. Bomback et al., "Development and validation of a patient self-assessment score for diabetes risk," Annals of Internal Medicine, vol. 151, no. 11, pp. 775-783, 2009.

[16] J. C. Eisenmann, "On the use of a continuous metabolic syndrome score in pediatric research," Cardiovascular Diabetology, vol. 7, article 17, 2008.

[17] Y. M. Hong, "Atherosclerotic cardiovascular disease beginning in childhood," Korean Circulation Journal, vol. 40, no. 1, pp. 1-9, 2010.

[18] K. E. Reed, D. E. R. Warburton, and H. A. McKay, "Determining cardiovascular disease risk in elementary school children: developing a healthy heart score," Journal of Sports Science and Medicine, vol. 6, no. 1, pp. 142-148, 2007.

[19] P. Brambilla, I. Lissau, C.-E. Flodmark et al., "Metabolic riskfactor clustering estimation in children: to draw a line across pediatric metabolic syndrome," International Journal of Obesity, vol. 31, no. 4, pp. 591-600, 2007.

[20] G. Bueno, L. A. Moreno, O. Bueno et al., "Metabolic risk-factor clustering estimation in obese children," Journal of Physiology and Biochemistry, vol. 63, no. 4, pp. 347-356, 2007.

[21] C. A. McMahan, S. S. Gidding, Z. A. Fayad et al., "Risk scores predict atherosclerotic lesions in young people," Archives of Internal Medicine, vol. 165, no. 8, pp. 883-890, 2005.

[22] "Type 2 diabetes in children and adolescents. American Diabetes Association," Diabetes Care, vol. 23, no. 3, pp. 381-389, 2000.

[23] M. Rodríguez-Morán, B. Salazar-Vázquez, R. Violante, and F. Guerrero-Romero, "Metabolic syndrome among children and adolescents aged 10-18 years," Diabetes Care, vol. 27, no. 10, pp. 2516-2517, 2004

[24] J. Steinberger, S. R. Daniels, R. H. Eckel et al., "Progress and challenges in metabolic syndrome in children and adolescents: a scientific statement from the American Heart Association Atherosclerosis, Hypertension, and Obesity in the Young Committee of the Council on Cardiovascular Disease in the Young; Council on Cardiovascular Nursing; and Council on Nutrition, Physical Activity, and Metabolism," Circulation, vol. 119, no. 4, pp. 628-647, 2009.

[25] P. Zimmet, G. Alberti, F. Kaufman et al., "The metabolic syndrome in children and adolescents," The Lancet, vol. 369, no. 9579, pp. 2059-2061, 2007. 
[26] P. Zimmet, G. K. M. M. Alberti, F. Kaufman et al., "The metabolic syndrome in children and adolescents-an IDF consensus report," Pediatric Diabetes, vol. 8, no. 5, pp. 299-306, 2007.

[27] M. C. Mancini, "Metabolic syndrome in children and adolescents-criteria for diagnosis," Diabetology \& Metabolic Syndrome, vol. 1, article 20, 2009.

[28] G. M. Reaven, "Banting lecture 1988. Role of insulin resistance in human disease," Diabetes, vol. 37, no. 12, pp. 1595-1607, 1988.

[29] S. M. Grundy, "Hypertriglyceridemia, insulin resistance, and the metabolic syndrome," American Journal of Cardiology, vol. 83, no. 9, pp. 25F-29F, 1999.

[30] E. Kassi, P. Pervanidou, G. Kaltsas, and G. Chrousos, "Metabolic syndrome: definitions and controversies," BMC Medicine, vol. 9, article 48, 2011.

[31] J. C. Eisenmann, K. R. Laurson, K. D. Dubose, B. K. Smith, and J. E. Donnelly, "Construct validity of a continuous metabolic syndrome score in children," Diabetology and Metabolic Syndrome, vol. 2, no. 1, article 8, 2010.

[32] L. B. Andersen and J. Haraldsdottir, "Tracking of cardiovascular disease risk factors including maximal oxygen uptake and physical activity from late teenage to adulthood. An 8-year follow-up study," Journal of Internal Medicine, vol. 234, no. 3, pp. 309-315, 1993.

[33] L. B. Andersen, M. Harro, L. B. Sardinha et al., "Physical activity and clustered cardiovascular risk in children: a cross-sectional study (The European Youth Heart Study)," The Lancet, vol. 368, no. 9532, pp. 299-304, 2006.

[34] C. A. McMahan, S. S. Gidding, G. T. Malcom, R. E. Tracy, J. P. Strong, and H. C. McGill Jr., "Pathobiological determinants of atherosclerosis in youth risk scores are associated with early and advanced atherosclerosis," Pediatrics, vol. 118, no. 4, pp. 14471455, 2006.

[35] L. B. Andersen, K. Müller, S. Eiberg et al., "Cytokines and clustered cardiovascular risk factors in children," Metabolism, vol. 59, no. 4, pp. 561-566, 2010.

[36] S. Ehtisham, N. Shaw, J. Kirk, and T. Barrett, "Development of an assessment tool for screening children for glucose intolerance by oral glucose tolerance test," Diabetes Care, vol. 27, no. 1, pp. 280-281, 2004.

[37] A. Boyd, J. Golding, J. Macleod et al., "Cohort profile: the 'children of the 90s'-the index offspring of the Avon Longitudinal Study of Parents and Children," International Journal of Epidemiology, vol. 42, pp. 111-127, 2013. 


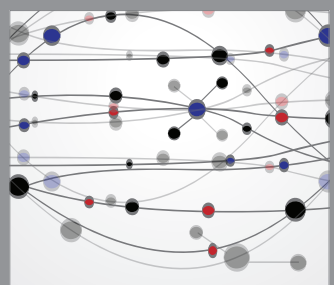

The Scientific World Journal
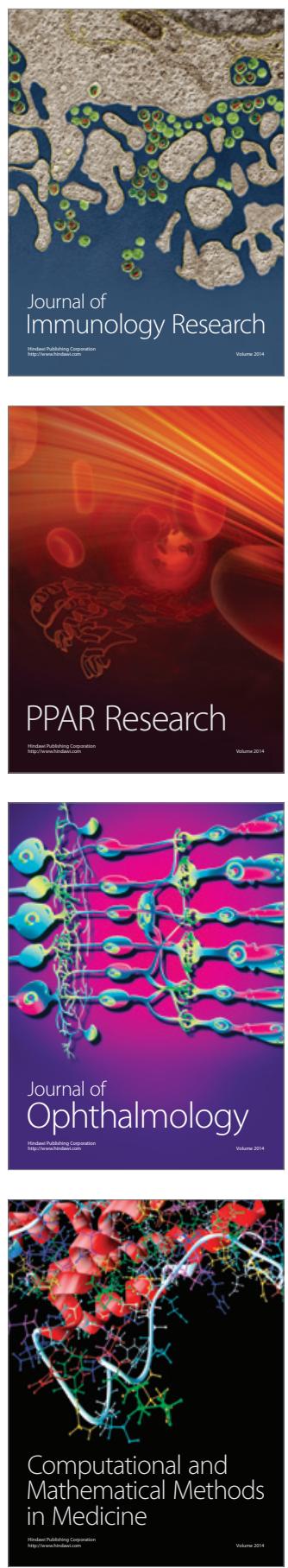

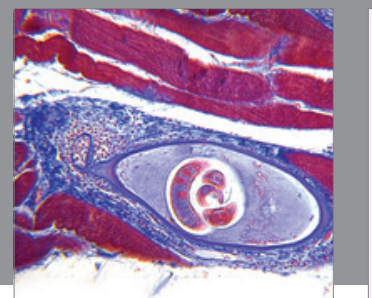

Gastroenterology

Research and Practice
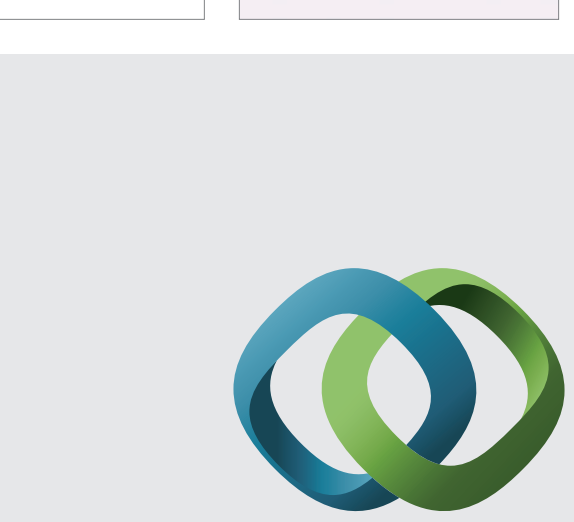

\section{Hindawi}

Submit your manuscripts at

http://www.hindawi.com
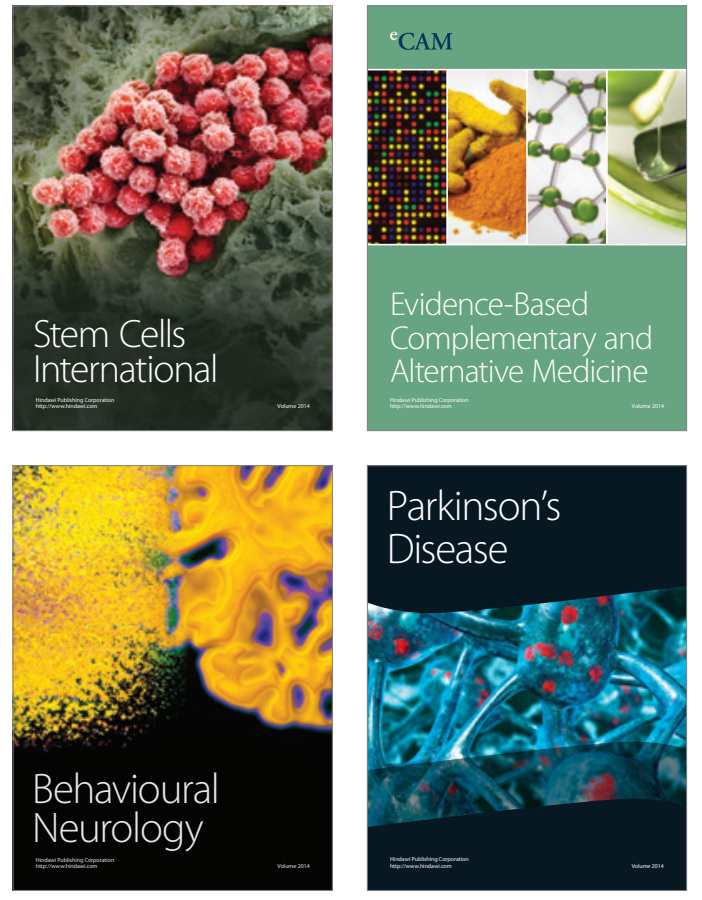
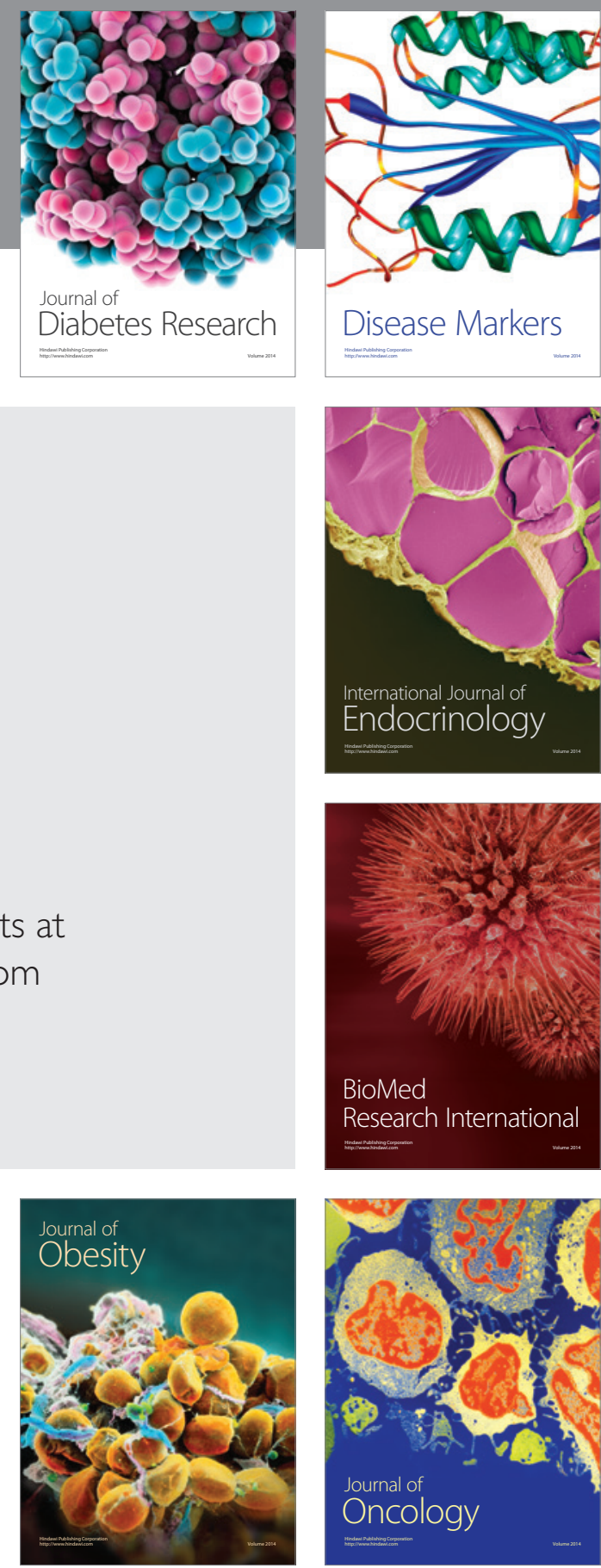

Disease Markers
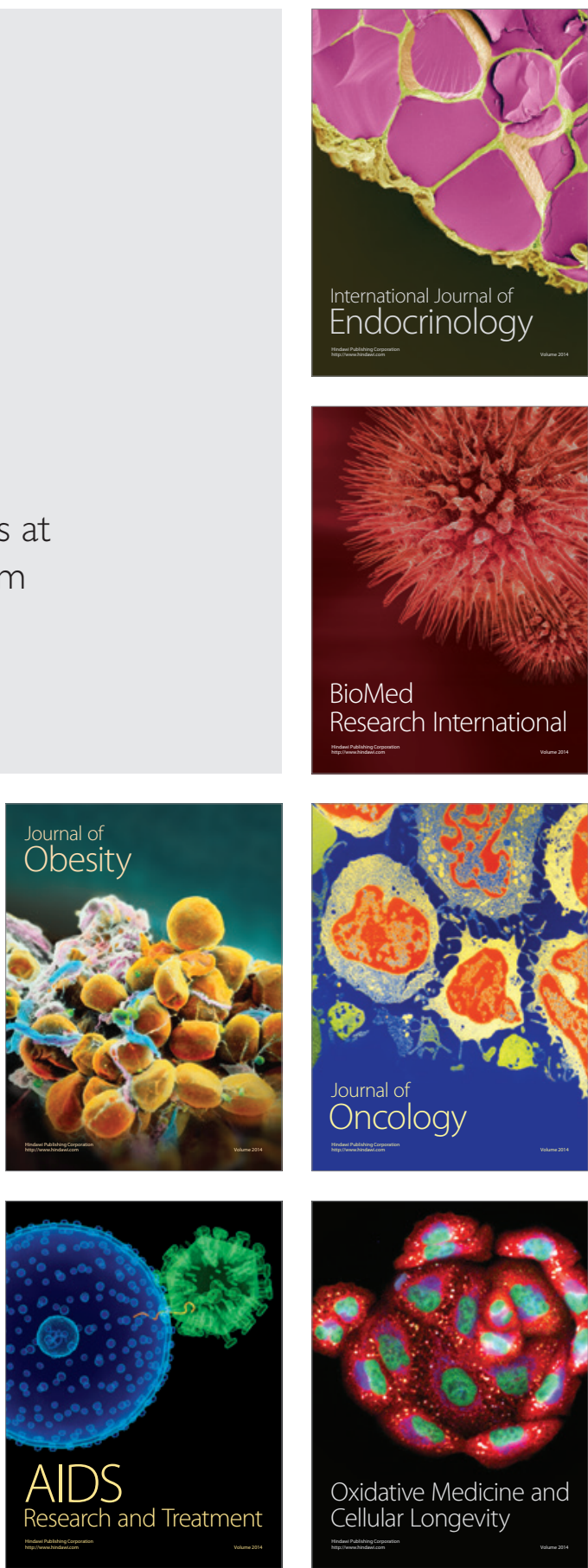